\title{
Effects of stress, communication relevance, and birth order on opinion change
}

ROBERT HELMREICH AND JOHN HAMILTON, DEPARTMENT OF PSYCHOLOGY, THE UNIVERSITY OF TEXAS, Austin, Tex. 78712

Subjects under high or low fear were presented with a communication: those under high fear showed significantly greater change on topics both relevant and irrelevant to the source of fear. There was a nonsignificant tendency for first-born Ss to show more change. Fear manipulation was confirmed by two stress measures, Mood Adjective Check List and Palmar Sweat Index.

A number of studies using fear-arousing communications have produced conflicting evidence regarding fear and attitude change. (See McGuire, 1966) One common element in most fear-attitude change studies is a confound introduced by the fear manipulation. Typically, different versions of the communication are used in different conditions with the more arousing communication including different or additional information designed to increase fear. This raises the possibility that differences other than simply fear-arousal account for some of the different attitude change reported in many studies.

An attempt to keep the communication constant was made in one study (Leventhal \& Trembly, in press), where the same film communication, projected to different sizes, was employed. No differences in attitude change were found among conditions using this technique.

The present study used a different technique to hold information corstant while varying induced fear. This was done by separating the fear arousal from the communication. Ss were put in a situation arousing two levels of fear and were then presented with a persuasive communication. This manipulation does not require that the communication be related to the source of stress.

Birth order of Ss was included as a factor because previous research (Helmreich, Kuiken, \& Collins, in press) has shown differential persuasibility under stress.

Method. The Ss were 86 undergraduate males in an introductory psychology course. Students were pretested on two topics. One topic, the value of using human Ss in research, was relevant to the stress manipulation; the other, the importance of a college education, was irrelevant. Ss were strongly in favor of both topics. ${ }^{2}$

The Ss reported individually to an $E$ who explained that he was studying changes in the palmar sweating rate as a "response to excitement or stimulation" in order to validate a method of measuring the Palmar Sweat Index. The method (Dabbs, Leventhal, \& Johnson, in press) involves daubing a finger of the $S$ with a black, plastic-base dye. Pressing a piece of cellophane tape against the finger produces a semi-transparent fingerprint in which the active sweat glands can be counted. Change in the number of active sweat glands is used as the response index. The PSI procedure was briefly explained to Ss.

The stress manipulation was introduced at this point. Low Stress Ss were told that electrical "stimulation" was being used as a "uniform stimulus" and that the PSI measure would be taken after each. It was emphasized that the stimulus would be painless. Ss were told that the first two trials would be scored and averaged for a "basic response rate at this stimulus level" against which to compare the latter three trials.

The E placed an electrode on one hand of the $S$, adjusted the shock apparatus and administered the stimulus. The PSI measure was taken as described above. Before going to the second trial, Ss were asked to complete a Mood Adjective Check List, a self report measure of emotional response (Radloff \& Helmreich, in press). A second trial using the same procedure was then administered.

The High Stress condition paralleled the low except that Ss were told that five noticeable "shocks" would be given. The first two shocks were of equal voltage to provide the "basic response rate." The remaining three shocks were described as being increasing voltages. The shock apparatus was set at a level which produced discomfort and, frequently, startle responses.
The attitude change manipulation was introduced in both conditions before the end of the second trial. An assistant entered the cubicle and explained that he needed to find some Ss for a few minutes to pretest some materials to be used in another study. The E reminded Ss that his study required only $20 \mathrm{~min}$ but gave $1 \mathrm{~h}$ of experimental credit and asked them to help out. All Ss complied with the request. The assistant then left the "pretest" forms to be given to the S at the end of the PSI study and left.

In all conditions the $\mathrm{E}$ explained after the second trial that he would have to leave the room for a few minutes to score the PSI for basic response rate before going on. He then gave Ss the pretest forms and suggested beginning the task while waiting "in order to save time at the end of the session."

The pretest required reading three short articles and rating them for clarity and content. The first and third articles were filler. The second article was either the relevant or irrelevant persuasive communication. As one of five ratings required after the article, Ss were asked their opinion on the topic in the same words used in the pretest. An 11-point Likert scale was used for all ratings.

The control was a "no communication" condition. S's pretest in this case was an attitude survey with no articles attached. Both topics were included along with eight filler items, so that control Ss served in both relevant and irrelevant conditions. Item order was alternated on the survey forms, but there was no order effect.

After Ss completed the attitude questionnaire, the purpose of the experiment was fully explained.

Results. The PSI and the MACL served as checks on the arousal manipulation. The results of both of these measures were analyzed with respect to birth order of Ss and stress condition. The means for the fear scale of the MACL are presented in Table 1. The difference between the two stress conditions is highly significant $(F=12.09$, df $=1 / 57, p<.001)$. Data from the PSI, also presented in Table 1 , confirm the effectiveness of the stress manipulation $(F=6.16, \mathrm{df}=1 / 57, \mathrm{p}<.015) .^{3}$

Having available both physiological and self report data for Ss, the agreement between the two measures was also examined. The correlation between the two was significant $\left(r=.41, p^{61}<.01\right)$.

Attitude change data are reported in the form of change scores and are summarized in Table 1. Differences between high and low stress conditions on attitude change are highly significant, $(\mathrm{F}=$ 11.83 , df $=1 / 76, p<.001)$. This strongly supports a fear facilitation position.

The birth order variable approaches but does not achieve significance at the .05 level, with a tendency for first borns to show more attitude change than later borns.

There is no reliable difference in attitude change for the relevant and irrelevant topics. The finding of significant change on

Table 1

First Bom

N Later Born $\mathbf{N}$

Means for Fear Scale of Mood Checklist (Experimental Ss)

\begin{tabular}{lllll}
\hline Low Stress & 20.14 & 17 & 18.04 & 13 \\
High Stress & 26.75 & 16 & 24.17 & 15
\end{tabular}

Palmar Sweat Scores of Active Sweat Glands

$\begin{array}{lllll}\text { Low Stress } & 47.19 & 17 & 50.71 & 13 \\ \text { High Stress } & 62.43 & 16 & 62.00 & 15\end{array}$

Means for Change Scores on Attitude Items

\begin{tabular}{lrrrr} 
Low Fear - Relevant & 1.70 & 10 & 0.20 & 5 \\
Low Fear - Irrelevant & 1.71 & 7 & 0.00 & 8 \\
High Fear - Relevant & 1.90 & 10 & 2.22 & 9 \\
High Fear - Irrelevant & 4.57 & 7 & 3.00 & 8 \\
Control & 0.10 & 22 & & \\
\hline
\end{tabular}


the irrelevant topic is important $(\mathrm{t}=3.49$, $\mathrm{df}=76, \mathrm{p}<.001)$ as an indication that stress may have a nonspecific facilitative effect on persuasibility.

In fear and persuasion studies in which fear is aroused by an informative communication, attitude change may represent a realistic response to threat. This is particularly likely when the communication concerns threats to future health and personal safety. It may be, however, that the arousal of fear in those studies has had an additional nonspecific facilitative effect of the type demonstrated in this study. What mixture of these two processes may have been involved cannot be determined from the data of this experiment.

The finding of nonspecific facilitation leads to several speculations. It may be that, because of stress, Ss are unable to attend to the communication closely. They may retain nothing more than the intent to persuade and may simply assume that the arguments are valid. Ss may be unable under stress to recall and evaluate their former position on the topic. Or they may mistrust the arguments, but doubt their own ability under the circumstances to counterargue, and may then assent to avoid having to defend their position. These suggestions are in keeping with the idea of loss of cognitive efficiency under stress (Janis \& Leventhal, in press) or restriction of cue utilization (Esterbrook, 1959).

Possible also is a tendency to acquiesce in situations of stress. Similar to the need to find support under stress might be the expedient of acquiescence. This could be with respect either to the communications and their persuasive intent or to the unknown communicator. Again Ss might be simply acquiescing to the questionnaire rating by giving what they think is the desired response. Ss may indiscriminately mark high agreement when asked their opinions under stress.
Another result of this study is validation of the PSI, a simple physiological index of arousal which should have many research applications.

\section{REFERENCES}

DABBS, J., LEVENTHAL, H., \& JOHNSON, J. The Palmar Sweat Index. $J$. exp. Psychol, in press.

ESTERBROOK, J. A. The effect of emotion on cue utilization and the organization of behavior. Psychol. Rev., 1959, 66, 183-201.

HELMREICH, R. L., KUIKEN, D., \& COLLINS, B. Effects of stress and birth order on attitude change. J. Pers., in press.

JANIS, I. L., \& LEVENTHAL, H. Human reactions to stress. In E. Borgatta and W. Lambert (Eds.), Handbook of personality theory and research. New York: Rand McNally, in press.

LEVENTHAL, H., \& TREMBLY, G. Negative emotions and persuasion. $J$. Pers, in press.

McGURRE, W. Attitudes and opinions. In Ann. Rev. Psychol, 1966, 17, 475-515.

RADLOFF, R., \& HELMREICH, R. Groups under stress: Psychological research in SEALAB II. New York: Appleton-Century-Crofts, Inc., in press.

\section{NOTES}

1. This research was supported by Contract Number N00014-67-A0126-0001 with the Office of Naval Research, Group Psychology Branch, Robert Helmreich, Principal Investigator.

2. Ten Ss were rejected for failure to meet this criterion. One was rejected for prior knowledge of the experiment.

3. Data on both manipulation checks are presented for experimental Ss only. Three Ss are missing from this analysis because their PSI prints were unscorable. 